УДК 656/6:005.591.6(045)

JEL Classification F 02, F 15, O 30, R 40

DOI 10.31375/2226-1915-2020-1-19-30

Н.Н. Примачева

к.э.н., доцент кафедри «Экономическая теория

и предпринимательство на морском транспорте» pnn170170@gmail.com

ORCID: 0000-0002-4206-5270

Национальный университет «Одесская морская академия», Одесса, Украина

И.М. Колегаев

к.э.н., ст. помощник капитана компании «Bourbon»

Kolegayevigor86@gmail.com ORCID: 0000-0002 1008-1727

Компания «Bоитbоп», Одесса, Украина

\section{ИННОВАЩИОННЫЕ ТЕХНОЛОГИИ В ИНТЕГРАЦИОННЫХ СТРАТЕГИЯХ МОРСКОЙ ТРАНСПОРТНОЙ ИНДУСТРИИ}

$\begin{array}{rrr}\text { Аннотация. Современное } & \text { состояние } \\ \text { глобального рынка морской торговли }\end{array}$ характеризуется постоянной изменчивостью по количественным и качественным характеристикам. При этом особой закономерностью развития становится усиление конкурентного противостояния операторских под систем $u$ формирование интеграчионных взаимодействий. Эти процессы нацелень на достижение сбалансированности состояния грузопотоков и провозной способности судов торгового флота. Однако этот процесс усложняется вследствие пассивности иеновых характеристик основных сегментов торгового судоходства. Поэтому ведушие судовладельческие структуры в основе развития используют инновачионные проекты. Кроме того, система администрирования параметров безопасности торгового судоходства на основе ужесточения стандартов и правил со стороны Международной морской организации ограничивает деятельности субстандартных судовладельческих структур. В этих условиях важно акиентировать внимание на достижении состояния сбалансированности рынка морской торговли. В соответствии с законами и механизмами рыночной эко-номики используются инструментарии управления и контроля результатами функииональной деятельности предприятий. Разнообразие условий функциональной и инвестиционной деятельности флота и портов в морских регионах предопределяет необходимость кониентрации внимания на приоритетных задачах развития. В тоже время в предпринимательской деятельности важнейшей задачей остается стимулирование.

$$
\text { Ключевые слова: инновационные }
$$
технологии, экономическая эффективность устойчивость позичионирования, конкуренция.
УДК 656/6:005.591.6(045)

JEL Classification F 02, F 15, O 30, R 40

DOI 10.31375/2226-1915-2020-1-19-30

Н.М. Примачова

к.е.н., доцент кафедри

«Економічна теорія

та підприємництво на морському транспорті»

Наиіональний університет «Одеська морська академія», Одеса, Украӥна

І.М. Колегасв

к.е.н., ст. помічник капітана компанії «Bourbon»

компанія «Bоиrbon», Одеса, Україна

ІННОВАЩЙН ТЕХНОЛОГЇ̈

В ІНТЕГРАЦІЙНИХ СТРАТЕГІЯХ

МОРСЬКОЇ ТРАНСПОРТНОЇ ІНДУСТРІЇ

Анотація. Поточний стан глобального ринку морської торгівлі характеризується постійною змінністю за кількісними та якісними характеристиками. При цуьому особою закономірністю розвитку стає посилення конкурентного протистояння операторських підсистем $i$ формування інтеграчійних взаємодій. Такі процеси націлено на досягнення збалансованості стану вантажопотоків $i$ провізної спроможності суден торговельного флоту. Однак ией проиес ускладнюється внаслідок пасивності цінових характеристик в основних сегментах торго-вельного судноплавства. Тому провідні судно-власницькі структури в основі розвитку використовують інновачійні проекти. Крім того, система адміністрування параметрів безпеки торговельного судноплавства на основі підвищення вимог до стандартів і правил з боку Міжнародної морської організачії обмежує діяльність субстандартних судновласницьких структур. В цих умовах важливо акцентувати увагу на до-сягненні стану відповідності обмеженням ринку морської торгівлі. Відповідно до законів $i$ меха-нізмів ринкової економіки використовуються інструментарії управління $i$ контролю результатами функціональної діяльності підприємств. Різноманітність умов функиіональної та інвестичійної діяльності флоту $i$ портів в морських регіонах зумовлює необхідність концентрації уваги на пріоритетних завданнях розвитку. У той же час y підприємницькій діяльності найважливішим завданням залишається стимулювання.

Ключові слова: інновачійні технологї, економічна ефективність, стійкість позииіонування, конкурениія. 


\author{
(C) Примачева Н.Н., Колегаев И.М., 2020 \\ UDC 656/6:005.591.6(045) \\ JEL Classification: F 02, F 15, O 30, R 40 \\ DOI 10.31375/2226-1915-2020-1-19-30
}

\author{
N. Primacheva \\ c. Ph.D., associate professor \\ of the Department of Economic Theory and Shipping on Marine Transport, \\ pnn170170@gmail.com \\ ORCID: 0000-0002-4206-5270 \\ National University «Odessa Marine Academy» \\ I. Kolegaev \\ c.n., Art. Assistant Captain, Bourbon \\ Kolegayevigor86@gmail.com \\ ORCID: 0000-0002-1008-1727 \\ «Bourbon», Odessa, Ukraine
}

\title{
INNOVATIVE TECHNOLOGIES IN THE INTEGRATION STRATEGIES OF THE MARINE TRANSPORT INDUSTRY
}

\begin{abstract}
Strengthen of the role of various innovative areas of development of marine transport subsystems is implemented in the system of stability and competitiveness of freight traffic services. Another consequence of innovative technologies is the change in capital intensity and cost of transportation of goods and passengers. The third result should consider the optimization of relations with the environment. At the same time, all of the mentioned above ensures the stability of the positioning of the enterprises of the marine transport industry in the structure of the maritime trade market, and the reduction of the technogenic load on the environment with the uncertainty in the formation of the profitability standard.

The large-scale positioning of subsystems of the marine transport industry in the global maritime trade market determines its economic results. At the same time, the complication of relations with the environment and the task of increasing the systemic security of the trade shipping conditions are increasing the role of innovative technologies in ensuring sustainable development. The current state of the global maritime trade market is characterized by constant variability in quantitative and qualitative characteristics. At the same time, a special regularity of development is the strengthening of the competitive opposition of operator subsystems and the formation of integration interactions. These processes are aimed at achieving a balanced state of cargo flows and the carrying capacity of merchant ships. However, this process is complicated by the passivity of the price characteristics of the main segments of merchant shipping. Therefore, the leading shipowning structures use innovative projects as the basis of development. In addition, the system for administering the safety parameters of merchant shipping on the basis of toughening standards and rules by the International Maritime Organization limits the activities of sub-standard ship ownership structures. In these conditions, it is important to focus on achieving a balanced state of the maritime trade market. The variety of conditions for the functional and investment activities of the fleet and ports in the marine regions determines the need to focus on development priorities. At the same time, stimulation remains the most important task in entrepreneurial activity.
\end{abstract}


Keywords: innovative technologies, economic efficiency, positioning stability, competition.

\section{Постановка проблемы.} Развитие любой подсистемы морской транспортной отрасли обусловливается жестким проявлением рыночных отношений, с одной стороны, a, c другой, характером требований к развитию на основе инновационных технологий. В структуре требований к последним особо выделяется инициатива Китая «Один пояс - один путь». Именно с позиции предпринима-тельских и глобальных интересов становится принципиальным выбор направлений дальнейшего развития морской транспортной индустрии.

Следует отметить, что среди основных задач эффективного позиционирования флота или портов на основе инновационных технологий выделяются рост производительности подсистем морской транспортной индустрии, снижение текущих затрат, качество и ускорение обслуживания транспортных потоков. Усиливается роль оптимизации техногенной нагрузки транспорта на окружающую среду.

$\begin{array}{ccc} & \text { Однако подходы к решению } \\ \text { этих } & \text { проблем } & \text { существенно }\end{array}$
различаются в сегменте грузовых перевозок и в сегменте обслуживания пассажиропотоков. Поэтому с учетом усиления роли морской транспортной индустрии принципиальным вопросом становится уточнение закономерностей конкурентного развития национальных составляющих глобального морского транспортного пространства.

В этом аспекте необходимо учитывать, что для любого предприятия важнейшей проблемой стано-вится эффективное управление потоком капитала по критериям сокращения потребности в его привлечении из внешних источников [1]. В торговом судоходстве эта стратегия реализуется на основе снижения денежных запасов и сменно-запасных частей, необходимых для устойчивой операторской деятельности. В этом же ряду стоит полнота сервисного обслуживания, краткосрочность ремонта и отсутствие простоев из-за отсутствия бункера.

Таким образом, принципиальным остается уточнение условий эффективного позиционирования морских транспортных предприятий в системно изменяющихся условиях количественных и качественных изменений параметров глобального рынка морской торговли.

Обзор

последних

исследований и публикаций. Любая внутренняя потребность в инновациях для удержания позиции торгового флота корректируется необходимостью рас-ширения интермодальных транспортных технологий. В этом отношении многообразие условий формирования предпринимательской эффективности морских транспортных предприятий в системе развития и функционирования международных транспортных коридоров отражает зависимость объема перевозок на данном направлении от основного качественного показателя работы времени доставки товаров.

Это

фактически

подтверждается проектом 
DEVELOPMENT OF MANAGEMENT

AND ENTREPRENEURSHIP METHODS ON TRANSPORT, № 1 (70), 2020
РОЗВИТОК МЕТОДІВ

УПРАВЛІННЯ ТА ГОСПОДАРЮВАННЯ

НА ТРАНСПОРТІ, № 1 (70), 2020 строительства подводного тоннеля между Хельсинки и Таллином. Вместо двух часов морской перевозки время для грузовых и пассажирских поездов сокращается до 30 минут. Проблемой становится наличие грузопотока и пассажиропотока, обеспечивающих эффективность инвестиций, объем которых проектируется в пределах 13 миллиардов евро. При современных экономических отношениях грузопоток недостаточен. Увеличение его возможно при использовании грузопо-токов экономических отношений Восток-Запад.

Тем не менее, рассмотрение альтернативных инновационных подходов к решению региональных транспортных задач требует рассмотрения их связи и с интермодальными транспортными коридорами. Поэтому. важно анализировать целесообразность реализации интеграционных проектов.

К сожалению, в Украине даже при формировании транспортных стратегий как до 2020, так и до 2030 годов представлены только лозунги «створення конкурентного середовища на ринку транспортних послуг» [2, с. 22] и не раскрыты ни механизм, ни инструментарий достижения ос-новных целей. При этом следует отметить, что рынок транспортных услуг характеризуется в силу альтернативности технологий и количества участников конкурентной средой. Тем не менее, проблемам развития морского транспорта с позиции альтернатив развития посвящены ряд исследований, среди которых обращаем внимание на $[3 ; 4$; 5].

Задачи исследования. Среди целей исследования выделяется систематизация современных условий эффективного позиционирования морских транспортных подсистем в рынке морской торговли по критериям соответствия внешним ограничениям.

При этом учитывается необходимость оценки адекватности инновационных вариантов развития флота и портов по экологическим и социальным параметрам.

Судоходные компании в эксплуатационной деятельности минимизируют страховой запас оборот-ного капитала. В соответствии с этим система функционирования в выб-ранном сегменте судоходства должна отвечать критериям минимума потери времени, с которым связаны все статьи эксплуатационных расходов. К сожалению, в Украине система тендерных закупок существенно огра-ничивает судовладельца ориентиро-ваться на ситуацию на рынках ресурсов. Особенно это касается объектов, сохранивших государственную форму управления. В акватории страны отсутствуют бункеровочные базы, что и сдерживает каботажное судоходство. Ибо на время перехода к месту бункеровки растут расходы с одновременной потерей рационального использования эксплуатационного периода.

Основной исследования. материал позицио-нирования предприятий морского транспорта в системе глобального рынка морской торговли на основе единых правил и 
DEVELOPMENT OF MANAGEMENT

AND ENTREPRENEURSHIP METHODS ON TRANSPORT, № 1 (70), 2020
РОЗВИТОК МЕТОДІВ

УПРАВЛНННЯ ТА ГОСПОДАРЮВАННЯ

НА ТРАНСПОРТІ, № 1 (70), 2020 стандартов тре-

особенностей

бует учета

устойчивого

функционирования

соответствующего сегмента морских перевозок. На первый план выдвигается конкурентный техникоэкономический уровень флота или портов и характер реализуемых интеграционных процессов.

При этом необходимо учитывать, что международный рынок морской торговли представляет собой динамично развивающийся комплекс взаимоотношений грузовладельцев и операторов. В основе его функционирования и развития лежат общие принципы экономических отношений, в основе которых выделяется обязательное возмещение затрат и формирование прибыли. Это предопределяет использование определенных закономерностей, среди которых особое место занимает экономичность участия в обслуживании мировой торговли. Именно приоритет уп-равления текущими затратами позволил Китаю завоевать лидирующие позиции в мировой торговле.

Одновременно китайские судоходные компании и торговые порты, используя мировые цены при более низких средних затратах, сформировали массу прибыли, которая обеспечивает финансирование их концессионных проектов на основных маршрутах национального экспорта. То есть, если не закономерностью, то тенденцией становится расширение инвестиционной деятельности отдельных операторов рынка морской торговли в иностранных портах на основе кредитования и длительного использования таких объектов, в основном торговых портов.

По сравнению с этим подходом проблемой равноправных рыночных условий позиционирования украинских портов считается завышенный уровень ставок канальных сборов при проходе к портам Николаев и Херсон. Их высокий уровень объясняется намерением повысить привлекательность портов Большой Одессы. Однако и в Одесском порту ставки портовых сборов относительно других портов Черного моря достаточно высоки.

Одновременно

конкурентоспособность портов Николаев и Херсон ограничивается режимом использования БДЛК по суточным и погодным условиям.

Существенные коррективы в организацию судоходства вносит стоимость докования и судоремонта, обеспечение социально-экономической гарантии работы экипажей в систему технической поддержки флота вносит ратификация Конвенции 2006 года. Особое место занимает выравнивание роли основного капитала судовладельцев, формирующего поток амортизационных затрат и человеческого капитала - в форме оплаты труда специалистов морских профессий.

Расширение роли экстернальных ограничений эффективности развития подсистем морского транспорта обусловливает повышение роли прин-ципа «экономия средств при гарантированном повышении экономической результативности работы». При этом изменяется 
DEVELOPMENT OF MANAGEMENT

AND ENTREPRENEURSHIP METHODS ON TRANSPORT, № 1 (70), 2020
РОЗВИТОК МЕТОДІВ

УПРАВЛНННЯ ТА ГОСПОДАРЮВАННЯ

НА ТРАНСПОРТІ, № 1 (70), 2020

соотношение между прямой и эмерджентной эффективностью позиционирования предприятия на рынке морской торговли.

Принципиальным становится управление инвестиционными потоками по уровню их окупаемости за счет оптимизации соотношения цены и средних затрат. В этом аспекте необходимо разделять два подхода, один основан на исключительно предпринимательских целях, другой ориентирован на государственные приоритеты и хозяйственную эффективность инновационных технологий. Поэтому прямые затраты владельцев судов могут и субсидироваться, как это обеспечивают отдельные страны при обслуживании национальной грузовой базы.

В отличие от развития терминальных объектов морских портов на основе концессионных ресурсов внимание в Украине акцентируется на оценке частных

$$
E_{\text {int }}=\frac{\sum Q_{i n}\left(t_{s}-t_{i n}\right) p_{c g} n_{w}}{T_{w}}(1+\varepsilon)\left(1+k_{r n}\right) \alpha_{t i}-\Delta K_{i n}>0
$$

где Q - количество груза, доставленного на основе реализации инновационной технологии транспортного обслуживания внешнеторговых отношений;

$\mathrm{t}$ - время доставки товаров на данном маршруте: s - стандартное и in - вследствие перехода на стандарты ускорения доставки грузов;

$P_{c g}$ - цена одной тонны продукции, находящейся в процессе доставки;

$n_{w}$ - норматив оборотных средств в формировании данного грузопотока; терминалов. И не государственная форма собственности отпугивает иностранных инвесторов. Это демонстрируют как Китайский фонд, так и структура WP Dubaj, реализуя повсеместно практику инвестиционной активности в иностранных портах. В морских транспортных проектах широко присутствует инвестиционный капитал альтернативных финансовых ресурсов. Главным становится оценка риска удержания затрат в пределах рыночного ценообразования.

Экономический эффект ускорения обработки грузовых потоков или обеспечения договорных сроков поставки товаров через данный транс-портный маршрут в системе международных транспортных коридоров в пределах жизненного цикла проекта может быть определен по условию $\varepsilon$ - доля кредитов, полученных грузовладельцами под оборотные фонды, занятые в товаре, находящемся в процессе доставки к месту потребления;

$$
k_{r n} \text { - ставка платы за кредитные }
$$
средства \$

$$
\Delta K_{\text {in }} \text { - приращение капитальной }
$$
стоимости судоходной компании по инновационным проектам.

При формировании и оценке целесообразности затрат в стратегии устойчивых конкурентных преимуществ судоходной компании необходимо учитывать совокупность 
DEVELOPMENT OF MANAGEMENT

AND ENTREPRENEURSHIP METHODS

ON TRANSPORT, № 1 (70), 2020
РОЗВИТОК МЕТОДІВ

УПРАВЛІННЯ ТА ГОСПОДАРЮВАННЯ

НА ТРАНСПОРТІ, № 1 (70), 2020 факторов, обеспечивающих приоритеты развития сервисных подсистем. В качестве критерия параметров, обес-печивающих экономичность поддер-жания работоспособности судов, рассматриваются ограничения по EBITDA. Так, конкурентоспособность азиатских судоремонтных пред-приятий выросла в значительной мере на основе понижения цен на соответствующие работы. Это в отличие от украинских предприятий достигнуто вследствие настойчивости повышения технологического уровня судостроения и судоремонта.

$$
\text { Для }
$$

отдельной судовладельческой или операторской компа- нии важнейшим становится оптими-зация объема перевозки груза в течение эксплуатационного периода при конкурентной производительности 1 тонны дедвейта. Именно этим предопределяется интенсивность проведения работ по формированию технической адекватности состояния судов компании.

$$
\text { Дифференциация этого }
$$

критериального показателя

относительно среднемирового уровня ограничивает сферу позиционирования национального судоходного потенциала. Так, Греция, наряду с другими странами, имеющими протяженную береговую линию и множество островов, интенсивно развивает высокоскоростное пассажирское судоходство и паромные сообщения.

К сожалению, в Украине вследствие потери базового производственного потенциала морская транспортная отрасль не рассматривалась в системе приоритетных, обеспечивающих системную безопасность участия в международном разделении труда. Современное ее состояние, с одной стороны, отражает проблемы неконкурентоспособности базовой составляющей морской транспортной индустрии, a, с другой, достаточно эффективное и в определенной степени динамичное развитие портовой составляющей.

Одновременно в основном на базе вторичного рынка формируется провозная способность флота инициативными судовладельческими группами. Достаточно четко реализуется принцип целесообразного подхода предпринимательских структур к выбору последовательности принятия соответствующих решений (рис. 1). 


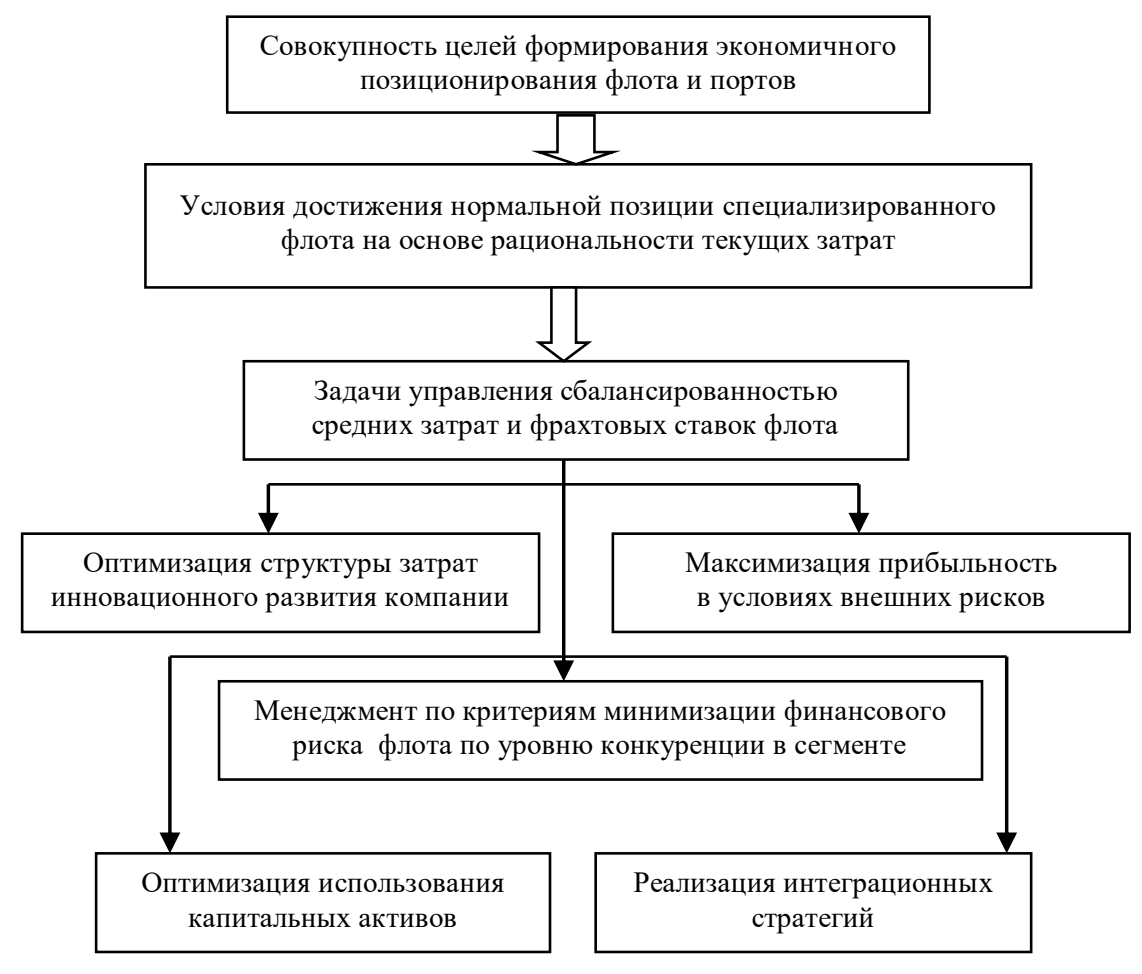

Рис. 1. Последовательность управления

конкурентным позиционированием флота в сегменте специализации

Источник: разработано авторами

Данные рис. 1 достаточно
четко демонстрируют логику формирования стратегии выбора альтернативных направлений развития относительно ограничений экономичности судоходства по совокупности внешних факторов и возможного развития с учетом остроты проблемы привлечения инвестиционных ресурсов. Именно это ограничение и сдержи-вает оптимизацию экономического потенциала морского транспорта Украины.

Когда развитие национального торгового флота реализуется в условиях пассивной морской транспортной политики, а бюджетная поддержка флоту национального 2 флага не гарантируется, возникает проблема оптимизации времени возмещения основной части кредита. При этом следует учитывать объективность утверждения, что капитал отражает всю совокупность распределенных во времени жизненного цикла активов. При их неадекватности конкурентным требованиям формируется риск экономичного функционирования и расходования, генерируемых хозяйственной деятельностью, потока фрахтовой выручки.

В соответствии с законами и механизмами рыночной экономики следует использовать инструментарий управления и контроля результатами 
DEVELOPMENT OF MANAGEMENT

AND ENTREPRENEURSHIP METHODS ON TRANSPORT, № 1 (70), 2020
РОЗВИТОК МЕТОДІВ

УПРАВЛІННЯ ТА ГОСПОДАРЮВАННЯ

НА ТРАНСПОРТІ, № 1 (70), 2020 функциональной

деятельности

предприятий [8]. Разнообразие

условий функциональной и инвестиционной деятельности флота и портов в морских регионах предопределяет необходимость концентрации внимания на приоритетных задачах развития. В то же время в предпринимательской деятельности, независимо от системы налогообложения, важнейшей задачей остается стимулирование, если не создания новых инновационных рабочих мест, то максимизации добавленной стоимости.

Отмеченное предопределяет характер реализации принципа и механизма оптимизации распределения грузопотоков между морским, железнодорожным, автомобильным и речным транспортами. Кроме чисто предпринимательских интересов необходимо учитывать и формирование эмерджентного эффекта рационализации использования транспортного комплекса страны.

Объективность приоритетного положения морского транспорта в глобальных экономических отношениях следует рассматривать в качестве важнейшего условия участия наземных видов транспорта в мультимодальных транспортных технологиях по требованиям торгового флота.

Вся совокупность внешних (национальных и глобальных), коммерческих и социальных подсистем регулирования торгового судоход-ного бизнеса имеет жесткие инте-ресы и сферу влияния. Именно это и усложняет выбор проектов оптимизации текущих затрат по предпринимательским целям.
Ограничивающим условием является статус безопасности и качество транспортного обслуживания [7] внешних и внутрен- них грузопотоков. При несоответ-ствии флота этим требованиям воз-никают противоречия и риски. Поэтому принципиальным становится выбор экономико-правового механизма вхождения в сегмент торгового судоходства.

Таким образом, хозяйственная деятельность и регулирование осуществляется в пределах экономической задачи увеличения прибыли на основе технико-экономической адекватности флота. В современных условиях усиления роли инновационных направлений развития флота формируется технико-экономический уровень технологии, обеспечивающий экономичность обслуживания грузопотоков. Мировая статистика раскрывает характер влияния работы морского транспорта на удорожание продукции за счет затрат на пере-возку в пределах 6-20 $\%$ в зависимости от рода товарной массы.

При этом в усилении позиции инновационного направления формирования производственного потенциала торгового флота выделяется внетранспортная составляющая системного результата.

$$
\text { Условия }
$$
развития приоритетных направлений торгового судоходства отражают ограничения развития дедвейта по критериям формирования предпринимательских и внешних эффектов. Так называемая воспринимаемая ценность грузовладельцами и другими потребителями услуг судоходных 
DEVELOPMENT OF MANAGEMENT

AND ENTREPRENEURSHIP METHODS ON TRANSPORT, № 1 (70), 2020
РОЗВИТОК МЕТОДІВ

УПРАВЛІННЯ ТА ГОСПОДАРЮВАННЯ

НА ТРАНСПОРТІ, № 1 (70), 2020 компаний предопределяется

экономией времени и стоимости доставки грузов. В системе временной сбалансированности тарифных ставок на рынке перевозок относительно эксплуатационных затрат формиру-ется ценность операторской деятельности [8]. В этом отношении и формирование маркетингового имиджа оператора судоходного рынка предопределяется дополнительными качествами.

$$
\text { В любом случае }
$$

определяющее значение для конкретного сегмента морского транспорта имеет рациональность расширения использования контейнерных технологий. Они обусловливают структуризацию флота и направления развития портов по критериям экономики масштаба. Определенную асимметрию вводил рост контейнерооборота, достигавший в среднегодовом исчислении $10 \%$ в период устойчивых торгово-экономических отношений. Только в текущем столетии мировой оборот по этой технологии возрос с 80 млн. до 400 млн. ТЕU в год.

Выводы. Независимо от степени интеграции производственного взаимодействия отдельных стран и концентрации грузопотоков даже в условиях инициативы «Один пояс - один путь» по приоритетам минимизации капитальных активов или операционных затрат, сохраняется роль ресурсных сырьевых потоков. Именно их транспортное обслуживание требует расширения роли стратегии лидерства по затратам. Это обусловлено не только сравнительной устойчивостью грузопотоков, но и непредвиденностью колебания тарифных ставок. При этом именно поквар-тальные колебания принципиально усложняют финансовое положение отдельных судоходных компаний, в составе которых имеются суда низкой грузоподъемности.

Следует отметить, что увеличение числа операторов при относительно медленном развитии мировой экономики приводит к росту конкуренции. Устойчивость, как это демонстрируют китайские и греческие судовладельческие структуры, достигается на основе особых подходов в национальных интересах [9].

Однако с учетом принципа многообразия при разнообразии условий сохраняются приоритеты развития специализированных подразделений морской транспортной инфраструктуры.

\begin{tabular}{lr}
\multicolumn{1}{l}{$\quad$ Приоритеты } & развития \\
специализированных & сегментов \\
торгового & судоходства \\
обусловливаются & совокупностью
\end{tabular} факторов, предопределяющих необходимость

дифференцированного подхода к участию национальной транспортной системы в международном разделении труда. К сожалению, интенсивность экологической нагрузки на характер подхода к выбору инвестиционных проектов судовладельцев усиливает требования к минимизации текущих затрат, чего невозможно достичь при ужесточении требований к различным сторонам безопасности мореплавания. 
DEVELOPMENT OF MANAGEMENT

AND ENTREPRENEURSHIP METHODS ON TRANSPORT, № 1 (70), 2020
РОЗВИТОК МЕТОДІВ

УПРАВЛІННЯ ТА ГОСПОДАРЮВАННЯ

НА ТРАНСПОРТІ, № 1 (70), 2020
Oт

деятельности компаний, операторской транспортных отличающейся конкурентной экономичностью, в том числе и от оффшорного судоходства, зависит реализация региональных программ концентрации и специализации производственных комплексов. Такой подход и характерен для традиционных морских государств, промышленность которых сосредоточена в приморских кластерах. Таким образом оптимизируются транспортные расходы в национальной экономике.

Это фактически отражает ориентацию на внутренние и на внешние рынки национальных производителей. В Украине такую стратегию реализует корпорация НИБУЛОН [10]. Среди характеристик функциональной отдельных важнейших эффективности деятельности составляющих логистической системы обра-ботки грузопотоков является время выполнения основной операции. Этим и предопределяется организация функциональной деятельности на основе использования технологических процессов, минимизирующих потери времени на выполнение технических, эксплуатационных и финансовых процедур. К сожалению, технологические процессы, связанные с техническим поддержанием надежности и работоспособности суд-на жестко регламентируются внешними условиями и конвенциональными критериями.

Поэтому и усиливается необходимость сосредоточения внима- ния на формирование совокупности условий, предопределяющих характер формирования текущих затрат операторской деятельности торгового флота.

\section{СПИСОК ЛІТЕРАТУРИ}

1. Бланк И.А. Управление использованием капитала. К.: Эльга, 2002. 656 c.

2. Транспортна стратегія України на період 2020 року. Киї: Міністерство інфраструктури Украӥни, 2011. 64 с.

3. Шевченко M. Maersk: логистическое решение «под ключ» // Порты Украинь,, № 6 (188), 2019. C. 36-37

4. Котлубай А. М. Проблемы теории и практики развития морского транспорта Украины. Одесса: ИПРиЭЭИ НАН Украины, 2011. 268 с.

5. Sotnichenko L., Solokha D. \& Bessonova S. Justification of business entities development based on innovate principles // Academy of Strategic Management Journal. Volumt 17. Issu 5, 2018. URL: https://www.abacademies.org/articles/justification-ofbusiness-entities-development-based-on-innovative-principles-7553.html

6. Фрасинюк T.I. Система забезпечення стійкості розвитку підсистем морської транспортної індустрії. Монографія. Одеса: НУ «ОМА», 2017. 304 c.

7. Моряков К. Проект для развития морской отрасли // Порты Украины, № 1 (173) 2018. C. $32-35$.

8. Колегаєв I. М. Принцииии конкурентного розвитку спеціалізованого судноплавства глобальної морської індустрії. Одеса: НУ «ОМУ», 2017. 332 c. 
9. Dykstra Don. L. Commercial Management in Shipping. London UK: Nautical Institute, 2005. 496 p.

10. Вадатурский А. В Украине нет проблемы переваливать объем экспорта в 60 млн. тонн // Порты Украины, 2019, № 6. С. 9-13.

11. Kosharskaya L., Makhurenko G., Postan M. Application of the system approach to the development of the project of a safety management system for navigation in Ukraine // Eastern-European Journal of Enterprise technologies. 2017. \#4/2 (36). P. 29-36. DOI:10.15587/2312-8372.2017.109094

12. Bubnova Galina V., Efimova Olga V., Karapetyants Irina V., Kurenkov Petr V. Digitalization of intellectualization of logistics of intermodal and multimodal transport // MATEC Web of Conferences 236(149):02013 - January 2018. DOI: 10.1051/ matecconf/201823602013

\section{REFERENCES}

1. Blank, Y. A. (2002). Upravlenye yspol'zovanyem kapytala [Capital management]. K.: Él'ha, 656 [in Russian].

2. Transportna stratehiya Ukrayiny na period 2020 roku [Ukraine's transport strategy for the period 2020] (2011). Kyyiv: Ministerstvo infrastruktury Ukrayiny, 64 [in Ukrainian].

3. Shevchenko, M. (2019). Maersk: lohystycheskoe reshenye «pod klyuch» [Maersk: turnkey logistics solution]. Porty Ukrayny - Ukrainian ports, № 6 (188), 36-37 [in Russian].

4. Kotlubay, A. M. (2011). Problemy teoryy y praktyky razvytyya morskoho transporta Ukrayny [Problems of theory and practice of development of maritime transport of Ukraine]. Odessa: YPRyÉÉY NAN Ukrayny, 268 [in Russian].

5. Sotnichenko, L. Solokha, D. \& Bessonova, S. (2018). Justification of business entities development based on innovate principles. Academy of Strategic Management Journal, 17 (5). Received from https://www.abacademies.org/articles/justification-ofbusiness-entities-development-based-on-innovative-principles-7553.html

6. Frasynyuk, T. I. (2017). Systema zabezpechennya stiykosti rozvytku pidsystem morskoyi transportnoyi industriyi [System for ensuring the sustainability of the subsystems of the maritime transport industry]. Odesa: NU «OMA», 304 [in Ukrainian].

7. Moryakov, K. (2018). Proekt dlya razvytyya morskoy otrasly [Project for the development of the maritime industry]. Porty Ukrayny - Ukrainian ports, № 1 (173), 32-35 [in Russian].

8. Kolehayev, I.M. (2017). Pryntsypy konkurentnoho rozvytku spetsializovanoho sudnoplavstva hlobal'noyi mors'koyi industriyi [Principles of competitive development of specialized shipping of the global maritime industry]. Odessa: $N U$ «OMU», 332 [in Ukrainian].

9. Dykstra Don. L. (2005). Commercial Management in Shipping. London UK: Nautical Institute, $496 \mathrm{p}$.

10. Vadaturskiy, A. V. (2019). Ukraine net problemy perevalivat' ob"yem eksporta v 60 mln. ton [In Ukraine there is no problem to transship the export volume of 60 million tons]. Porty Ukrayny - Ukrainian ports, № 6, 9-13 [in Russian].

11. Kosharskaya, L., Makhurenko, G. \& Postan, M. (2017). Application of the system approach to the development of the project of a safety management system for navigation in Ukraine. Eastern-European Journal of Enterprise technologies. \#4/2 (36), 29-36. DOI:10.15587/2312-8372.2017.109094. 
12. Galina V. Bubnova, Olga V. Efimova, Irina V. Karapetyants \& Petr V. Kurenkov (2018). Digitalization of intellectualization of logistics of intermodal and multimodal transport. MATEC Web of Conferences 236(149):02013 - January 2018. DOI: 10.1051/matecconf/201823602013.

Стаття надійшла до редакиії 25.02.2020

Посилання на статтю: Примачева Н.Н., Колегаев И.М. Инновационные технологии в интеграционных стратегиях морской транспортной индустрии // Розвиток методів управління та господарювання на транспорті: Зб. наук. праць, 2020. № 1 (70). С. 1930. DOI 10.31375/2226-1915-2020-1-19-30.

Article received 25.02.2020

Reference a JournalArtic: Primacheva, N. \& Kolegaev, I. (2020). Innovative technologies in the integration strategies of the marine transport industry. Development of management and entrepreneurship methods on transport, 1(70), 19-30. DOI 10.31375/2226-1915-2020-1-19-30. 